\title{
Analisis Kontras Optis Lapisan Lilin Lebah pada Buah Tomat dengan Metode Laser Speckle Imaging
}

\author{
Khairini Fitri*, Harmadi \\ Jurusan Fisika, Universitas Andalas \\ *khairini_fitri@yahoo.co.id
}

\begin{abstract}
ABSTRAK
Analisis kontras optis lapisan lilin lebah pada buah tomat dengan metoda Laser Speckle Imaging (LSI) telah dilakukan. Penelitian ini dilakukan untuk mengamati perubahan pola spekel akibat pengaruh variasi konsentrasi lilin lebah. Pola spekel dianalisis menggunakan software ImageJ dan Matlab, sehingga diperoleh karakteristik histogram distribusi intensitas serta ukuran bulir spekel. Penyinaran dilakukan pada sampel sebelum dan setelah dilapisi lilin lebah dengan variasi konsentrasi $2 \%, 4 \%, 6 \%, 8 \%, 10 \%$ dan $12 \%$. Hasil penelitian menunjukkan bahwa terdapat korelasi antara konsentrasi lapisan lilin lebah dengan nilai kontras dan ukuran bulir spekel. Semakin tinggi konsentrasi lapisan lilin lebah, maka nilai kontras dan ukuran bulir spekel akan semakin menurun.

Kata kunci: pola spekel, kontras spekel, ukuran bulir spekel
\end{abstract}

\section{ABSTRACT}

Optical contrast analysis of beeswax on tomato with laser speckle imaging method has been conducted. The research was conducted to see change of speckle pattern due to influence of beeswax concentration variations. Speckle patterns was analyzed using ImageJ and Matlab, in order to obtain the characteristics of the intensity distribution histogram and size of speckle. The radiation was conducted on samples before and after coated with beeswax with various consentrations of $2 \%, 4 \%, 6 \%, 8 \%, 10 \%$ and $12 \%$. The results show that there is a correlation between concentration of beeswax coating and contrast value and size of speckle. The higher the concentration of beeswax is given, the lower contrast value and size of speckle.

Keywords: speckle pattern, kontras speckle, size of speckle

\section{PENDAHULUAN}

Buah tomat merupakan salah satu komoditas hortikultura yang memiliki kandungan air yang cukup tinggi, yaitu lebih dari $93 \%$. Kadar air yang tinggi umumnya mengakibatkan daya simpan rendah, susut bobot tinggi akibat penguapan (transpirasi), pernapasan (respirasi), perubahan fisik (keriput), pertumbuhan mikroba, serta perubahan fisikokimia buah menjadi cepat (Hartuti, 2006). Untuk itu diperlukan usaha untuk mencegah laju kemunduran dan proses kerusakan tersebut agar berjalan lambat.

Menurut Winarno dan Wirakartakusumah (1981), salah satu usaha yang dilakukan untuk mencegah kerusakan pasca panen sekaligus mempertahankan umur simpan akibat laju respirasi dan transpirasi adalah dengan melakukan pelapisan lilin (waxing). Pelapisan lilin merupakan teknik penundaan kematangan yang bertujuan menghambat sirkulasi udara dan menghambat kelayuan. Hal ini mengakibatkan produk yang disimpan tidak cepat kehilangan berat karena adanya transpirasi, serta mencegah/menghambat respirasi pada buah yang menyebabkan umur simpan buah makin lama.

Tebal lapisan lilin yang digunakan juga harus diperhatikan. Winarno (1981) menjelaskan, tebal lapisan lilin yang digunakan harus seoptimal mungkin. Jika terlalu tipis, maka usaha dalam menghambat respirasi dan transpirasi kurang efektif. Lapisan yang terlalu tebal memungkinkan tertutupnya semua pori-pori (stomata) komoditi. Apabila semua pori-pori tertutup maka akan mengakibatkan terjadinya respirasi anaerob. Respirasi anaerob merupakan respirasi yang terjadi tanpa menggunakan $\mathrm{O}_{2}$, sehingga sel melakukan perombakan di dalam tubuh buah itu sendiri yang dapat mengakibatkan proses pembusukan lebih cepat dari keadaan yang normal (Roosmani, 1975).

Untuk mendeteksi lapisan lilin pada buah diperlukan pengujian secara non-destructive terhadap sampel yang akan diuji. Salah satu teknik imaging non-destructive yang digunakan untuk mendeteksi sinyal optik dari jaringan biologi adalah metode Laser Speckel Imaging (LSI) (Rabal dan Braga, 2009). Pada metode ini, material disinari berkas koheren dari laser sehingga terjadi hamburan dan membentuk pola spekel pada bidang pengamatan (Ansari dan Nirala, 
2012). Sistem pencitraan spekel mendeteksi perubahan intensitas spekel laser yang didifraksikan pada sampel dengan analisis kontras spekel (Tamaki dkk, 1994). Analisis kontras yang digunakan adalah analisis intensitas gray level (tingkat keabu-abuan) dari hasil citra suatu sistem pencitraan spekel laser dengan menggunakan histrogram yang digunakan untuk klasifikasi dan pencocokan pola (Aspari, 2009). Sistem LSI ini memiliki kesederhanaan dalam pengesetan karena hanya terdiri dari tiga komponen utama yaitu laser sebagai sumber cahaya, sampel dan sebuah detektor cahaya. Keunggulan LSI adalah minim efek samping (nondectructive, non-invasive, non-ionisasi) (Apsari, 2009), memiliki pencitraan penuh, akuisisi data langsung, akurat, kuantitatif dan biaya rendah (Harmadi, 2011).

\section{METODE}

\subsection{Alat dan Bahan}

Alat dan bahan yang digunakan dalam penelitian ini terdiri dari laser $\mathrm{He}-\mathrm{Ne} 632,8 \mathrm{~nm}$ sebagai sumebr cahaya, detektor 640x480 piksel berupa CCD (Charge Cople Device) $30 \mathrm{fps}$ (frame per second), PC, kotak dari akrilik hitam, pemanas air, hoteplate, timbangan digital, gelas ukur, lilin lebah, trietanolami dan asam oleat sebagai emulfisier, serta buah tomat.

\subsection{Preparasi Sampel Buah dan Preparasi Larutan Lilin Lebah}

Buah tomat dibersihkan dengan menggunakan air bersih dan dikeringkan. Kemudian dilakukan pembuatan emulsi lilin lebah dengan variasi konsentrasi $0 \%, 2 \%, 4 \%, 6 \%, 8 \%$, $10 \%, 12 \%$. Pembuatan emulsi menggunakan perbandingan lilin : TEA : asam oleat, 6:2:1. Dan volume larutan yang digunakan adalah $250 \mathrm{ml}$.

\subsection{Penyusunan Sistem Pencitraan Optis dengan Metose LSI}

Penyusunan sistem pencitraan optis dengan metode LSI terdiri dari sumber laser $\mathrm{He}-\mathrm{Ne}$ dengan $\lambda=632,8 \mathrm{~nm}$ berdaya keluaran $0,8 \mathrm{~mW}$. Sensor kamera CCD 30 fps seri A4tech model PK-836F dan PC (Personal Computer) dengan software Ulead VideoStudio-10 sebagai komponen display visual untuk merekam dan menampilkan pola spekel. Perangkat LSI diletakkan dalam kotak kedap cahaya, dari bahan akrilik. Susunan rancangan sistem LSI dapat dilihat pada Gambar 1 .

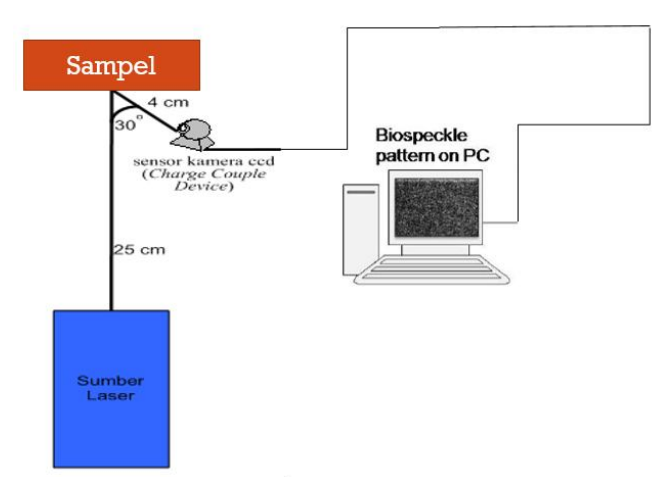

Gambar 1 Susunan rancangan sistem LSI

Jarak optimum sumber cahaya terhadap sampel uji yang digunakan pada penelitian ini adalah $25 \mathrm{~cm}$, sesuai dengan panjang rongga (cavity lenght) laser He-Ne (Griot, 2005). Jarak sampel ke sensor kamera CCD adalah $4 \mathrm{~cm}$ dan sudut optimum yang digunakan untuk mendapatkan citra adalah $30^{\circ}$ (Zdunek dan Cybulska, 2011). Pengambilan citra spekel masingmasing buah tomat diambil pada sepuluh titik secara acak yang kemudian dirata-ratakan. CCD diarahkan tepat pada buah tomat sehingga ditangkap hasil dari penyinaran laser berupa pola spekel yang ditampilkan pada PC.

\subsection{Pengolahan Citra Pola Spekel untuk Mendapatkan Kontras Spekel}

Pola gelap terang dari spekel terjadi karena frekuensi yang berbeda, dimana pola gelap lebih dominan dari pada pola terang. Berdasarkan deskripsi tentang statistik distribusi intensitas 
yang dihasilkan oleh spekel, diasumsikan bahwa medan yang koheren dengan panjang gelombang $\lambda$ menerangi permukaan suatu bahan. Panjang gelombang yang dipilih memiliki ukuran yang lebih kecil dari bahan yang digunakan. Kekasaran suatu bahan akan menyebabkan distribusi keadaan yang acak.

Medan cahaya pada titik tertentu $\mathrm{P}$ (x, y, z) dalam pola spekel merupakan jumlah dari total hamburan $\mathrm{N}$, yang mewakili distribusi dari semua titik pada permukaan hamburan. Dalam pencahayaan dengan cahaya monokromatik dan cahaya yang dipolarisasikan secara penuh, konstribusi dari medan pada keadaan $\mathrm{P}$ yang dihasilkan oleh setiap elemen permukaan, $j$, dijabarkan (Rabal dan Braga, 2009), diberikan oleh Persamaan 1:

$$
u_{j}(P)=\left|u_{j}\right| e^{i \Phi_{j}}=\left|u_{j}\right| e^{i k r_{j}}
$$

$r_{j}$ adalah jarak (variasi acak) dari elemen hamburan permukaan ke $j$ pada titik P. Amplitudo kompleks medan hamburan di titik P dituliskan pada Persamaan 2 sebagai:

$$
U(P)=\frac{1}{\sqrt{N}} \sum_{j=1}^{N} u_{j}(P)=\frac{1}{\sqrt{N}} \sum_{j=1}^{N}\left|u_{j}\right| e^{i \Phi_{j}}=\frac{1}{\sqrt{N}} \sum_{j=1}^{N}\left|u_{j}\right| e^{i k r_{j}}
$$

Tambahan dalam Persamaan 2 merupakan cara acak dalam bidang kompleks dengan fasa acak $\phi_{j}=k r_{j}$.

Dengan mengasumsikan amplitudo $u_{j}$ dan fasa $\phi_{j}$ pada setiap komponen medan secara statistik independen (bebas/tidak bergantung) satu sama lain, dan tidak bergantung dari amplitudo dan fasa komponen medan lainnya. Fasa $\phi_{j}$ didistribusikan secara menyuluruh pada interval $(-\pi, \pi)$, yang berarti bahwa permukaan kasar dibandingkan dengan panjang gelombang, dan jumlah hamburan total $\mathrm{N}$ sangat besar, sehingga menjamin validitas dari teorema limit sentral. Goodman telah menunjukkan bahwa bagian riel dan imajiner dari medan resultan adalah asimtotik Gaussian (Goodman, 1976 dan 1984). Fungsi densitas probabilitas bersama diberikan oleh Persamaan 3:

$$
P_{r, i}=\left(U^{(r)}, U^{(i)}\right)=\frac{1}{2 \pi \sigma^{2}} \exp \left[\frac{\left(\left(U^{(r)}\right)^{2}+\left(U^{(i)}\right)^{2}\right)}{2 \sigma^{2}}\right]
$$

dengan nilai Circular Gaussian,

$$
\sigma^{2}=\lim _{N \rightarrow \infty} \sum_{j=1}^{N} \frac{\left\langle\left|u_{j}\right|\right\rangle^{2}}{2}
$$

Dari Persamaan 3, dan dengan menghitung intensitas $I$ dan fasa $\phi$ medan resultan pada bagian riel dan imajiner medan mengacu pada Persamaan 5.

$$
\begin{aligned}
& U^{(r)} \sqrt{I} \cos \Phi \\
& U^{(r)} \sqrt{I} \sin \Phi
\end{aligned}
$$

Selanjutnya probabilitas intensitas $p(I)$ dan probabilitas fasa $p(\phi)$, diberikan oleh Persamaan 6 dan Persamaan 7.

$$
\begin{gathered}
p(I)=\frac{1}{\sqrt{1}} e^{-\frac{I}{\langle I\rangle}} \text { untuk } I \geq 0 \\
p(\Phi)=\frac{1}{2 \pi} \text { untuk }-\pi \leq \Phi \leq \pi
\end{gathered}
$$

Dalam Persamaan 6, $\langle>\rangle$ adalah nilai rata-rata intensitas pada diagram spekel. Berdasarkan dua persamaan terakhir, distribusi intensitas mengikuti hukum eksponensial negatif dimana fasa didistribusi secara merata dalam interval $(-\pi, \pi)$. Distribusi kejadian intensitas didefenisikan pada Persamaan 8 , 


$$
\langle I\rangle=n !\left(2 \sigma^{2}\right)^{n}=n !\langle I\rangle^{n}
$$

khusus pada orde kedua dinyatakan dalam Persamaan 9.

$$
\left\langle I^{2}\right\rangle=2\langle I\rangle^{2} \text { dan } \sigma_{I}^{2}=\left\langle I^{2}\right\rangle-\langle I\rangle^{2}=\left\langle I^{2}\right\rangle
$$

Persamaan ini menunjukkan bahwa standar deviasi dari pola spekel terpolarisasi sama dengan nilai rata-rata intensitas. Dengan menghitung pola modulasi spekel yang dinyatakan sebagai kontras, didefenisikan pada Persamaan 10.

$$
C=\frac{\sigma_{I}}{\langle I\rangle}
$$

Kontras merupakan gabungan dari pola spekel yang menjadi kesatuan. Berdasarkan persamaan di atas, $\langle I\rangle$ adalah nilai rata-rata intensitas, $\sigma_{I}$ adalah standar deviasi dari intensitas, dan $C$ adalah kontras.

\subsection{Analisis Ukuran Bulir Spekel}

Chipouline (2011) menjelaskan, untuk menghitung ukuran spekel, dianggap permukaan kasar disinari cahaya koheren. Medan gelombang cahaya $\mathrm{U}_{\mathrm{o}}(\mathrm{x})$ yang membentuk distribusi medan pada permukaan $\mathrm{U}_{\mathrm{o}}\left(\mathrm{x}_{\mathrm{o}}\right)$, dan permukaan mempunyai profil geometri $\mathrm{s}\left(\mathrm{x}_{\mathrm{o}}\right)$ seperti terlihat pada Gambar 2. Cahaya dipantulkan dari permukaan dengan probabilitas fase dan amplitudo yang sama. Selain itu profil permukaan haruslah lebih besar dari panjang gelombang cahaya yang digunakan. Ukuran spekel dapat dihitung dengan pendekatan statistik fase permukaan dan menganggap gelombang cahaya dari permukaan ke titik $\mathrm{P}$.

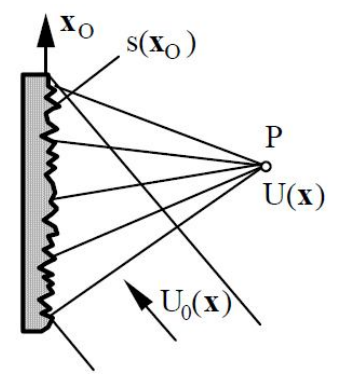

Gambar 2 Parameter dasar untuk mengukur pola spekel

(Sumber: Chipouline, 2011)

Celah sumber dilambangkan dengan $A_{o}$ ukuran spekel diperoleh dari perkalian dengan rumus permukaan $A_{s}$, diperlihatkan pada Persamaan 11 .

$$
A_{s} \cdot A_{o}=(\lambda z)^{2}
$$

Dimana $z$ merupakan jarak antara permukaan dengan bidang pengamat. Jika sumber cahaya berbentuk lingkaran dengan diameter $D=(\Delta x)_{o}$ dan jarak sumber bidang pengamat $d$, maka didapat Persamaan 12.

$$
A_{s}=\frac{(\lambda z)^{2}}{A_{o}}=\frac{(\lambda z)^{2}}{\frac{\pi D^{2}}{4}}=\frac{4 \lambda^{2} d^{2}}{\pi D^{2}}
$$

Luas sumber cahaya adalah $A_{o}=\pi D^{2} / 4$, sehingga luas permukaan spekel (ukuran spekel $\Delta x_{s}$ ) diperlihatkan pada Persamaan 13.

$$
\begin{aligned}
& \frac{4 \lambda^{2} d^{2}}{\pi D^{2}}=\frac{\pi\left(\Delta x_{s}\right)^{2}}{4} \\
& \left(\Delta x_{s}\right)^{2}=\frac{16 \lambda^{2} d^{2}}{\pi^{2} D^{2}}
\end{aligned}
$$




$$
\left(\Delta x_{s}\right)=\frac{4 \lambda d}{\pi D}=\frac{1,27 \lambda d}{D}
$$

\section{HASIL DAN DISKUSI}

\subsection{Korelasi Kontras Spekel dengan Konsentrasi Emulsi Lilin}

Hasil pencitraan pola spekel yang diolah menggunakan software ImageJ terlihat secara umum berupa pola gelap terang yang bervariasi dan didistribusikan secara acak dimana bintik gelap lebih banyak daripada bintik terang. Gambar 3 merupakan perbandingan pola spekel pada buah tomat sebelum dilapisi lilin lebah dengan yang sudah dilapisi lilin lebah. Pada Gambar 3 (a) dapat dilihat struktur berupa buliran halus pada permukaan buah tomat. Setelah dilapisi emulsi lilin lebah, pola spekel yang terbentuk semakin rapat, seperti yang terlihat pada Gambar 3 (b) dan (c). Hal ini terjadi karena permukaan buah tomat yang awalnya tidak rata, setelah dilapisi emulsi lilin lebah menjadi lebih rata.

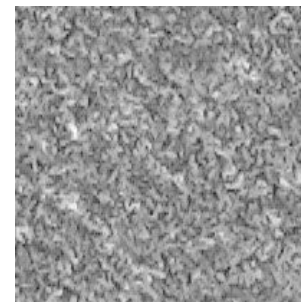

(a)

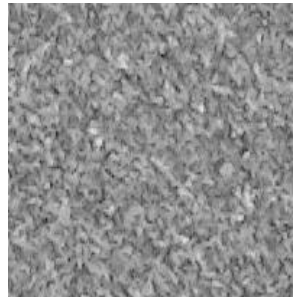

(b)

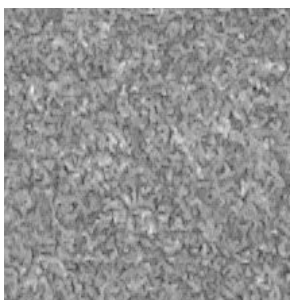

(c)

Gambar 3 (a) Pola spekel buah tomat sebelum dilapisi lilin lebah, (b) pola spekel tomat setelah dilapisi lilin lebah 6\%, dan (c) pola spekel tomat setelah direndam lilin lebah $12 \%$.

Tabel 1 Nilai kontras buah tomat sebelum dilapisi lilin lebah

\begin{tabular}{ccr}
\hline No. & Sampel & Nilai Kontras (a.u) \\
\hline 1. & 1 & 0,105986 \\
\hline 2. & 2 & 0,093297 \\
\hline 3. & 3 & 0,088161 \\
\hline 4. & 4 & 0,086961 \\
\hline 5. & 5 & 0,088164 \\
\hline 6. & 6 & 0,088022 \\
\hline 7. & 7 & 0,088161 \\
\hline 8. & 8 & 0,093297 \\
\hline 9. & 9 & 0,086961 \\
\hline 10. & 10 & 0,088022 \\
\hline 11. & 11 & 0,088164 \\
\hline 12. & 12 & 0,093297 \\
\hline 13. & 13 & 0,088022 \\
\hline 14. & 14 & 0,088164 \\
\hline 15. & 15 & 0,088161 \\
\hline 16. & 16 & 0,093297 \\
\hline 17. & 17 & 0,086961 \\
\hline 18. & 18 & 0,088164 \\
\hline & Rata-rata $($ a.u) & 0,090070 \\
\hline & Standar deviasi $($ Sn) & 0,004615 \\
\hline & Ketelitian $(\%)$ & 99,995385 \\
\hline & Presentase kesalahan $(\%)$ & 0,025637 \\
\hline & &
\end{tabular}

Secara keseluruhan nilai kontras spekel buah tomat sebelum direndam dengan lapisan lilin lebah dapat diamati melalui Tabel 1. Berdasarkan Tabel di bawah dapat dilihat bahwa nilai kontras untuk setiap sampel uji relatif sama sebelum dilapisi lilin lebah. Hal ini dapat dilihat dari nilai standar deviasi sebesar 0,004615 dengan ketelitian 99,995385\% dan tingkat kesalahan 
0,025637\%. Data statistik yang diperoleh ini menunjukkan nilai kontras buah tomat sebelum dilapisi lilin lebah relatif sama, berkisar 0,090070 a.u.

Secara teori, Goodman (1975) menjelaskan bahwa kontras spekel memiliki nilai antara 0 dan 1 . Kontras spekel bernilai 1 menunjukkan nilai probabilitas intensitas bernilai maksimum, sedangkan kontras yang bernilai 0 berarti tidak ada pola spekel yang teramati atau tidak jelas/buram (Boas dan Dunn, 2010). Idealnya kontras spekel tidak ada yang bernilai 1, karena pada jaringan biologis terdapat lapisan yang menyebabkan interferensi cahaya pada permukaan yang disinari laser, sehingga nilai kontras spekel berada pada rentang 0 dan 1 .

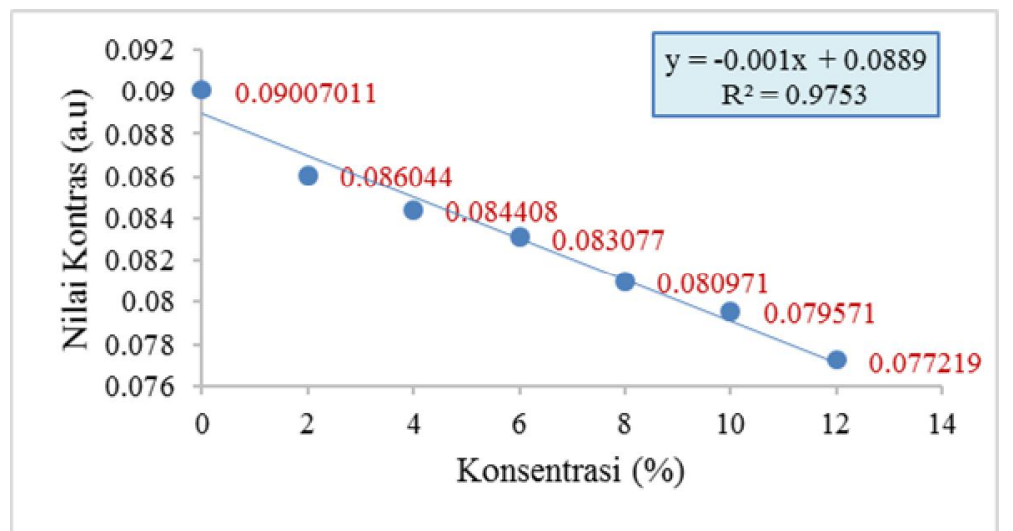

Gambar 4 Sampel setelah dilapisi lilin lebah dengan variasi konsentrasi

Nilai kontras buah tomat yang dilapisi lilin lebah dengan variasi konsentrasi secara umum tampak pada Gambar 4. Berdasarkan gambar tersebut dapat dilihat perubahan nilai kontras spekel buah tomat yang dilapisi lilin lebah dengan variasi konsentrasi. Berdasarkan fungsi transfer yang diperoleh dapat dilihat hubungan perubahan nilai kontras terhadap kenaikan nilai konsentrasi yaitu $y=-0,001 x+0,00889$. Variabel $x$ merupakan besaran untuk konsentrasi emulsi lilin lebah dan y adalah besaran untuk nilai kontras. Fungsi tersebut menunjukkan bahwa setiap perubahan konsentrasi emulsi lilin lebah sebesar $1 \%$ mengakibatkan perubahan nilai kontras sebesar 0,001 a.u. Nilai 0,00889 merupakan nilai offset yang menyatakan bahwa nilai kontras buah tomat sebelum dilapisi emulsi lilin lebah adalah sebesar 0,00889 a.u. Menurunnya nilai kontras dipengaruhi oleh konsentrasi lapisan lilin lebah yang semakin besar. Hal ini dapat dilihat pada arah regresi yang bernilai negatif $(-0,001)$. Selain itu nilai koefisien kolerasi $\left(\mathrm{R}^{2}\right)$ 0,9753 memperlihatkan bahwa adanya hubungan erat antara konsentrasi lapisan lilin lebah dengan nilai kontras spekel yang dihasilkan.

\subsection{Korelasi Ukuran Bulir Spekel dengan Konsentrasi Emulsi Lilin Lebah}

Perhitungan ukuran bulir spekel dilakukan dengan menggunakan metoda atuokorelasi pada Matlab. Gambar 5 merupakan grafik yang menunjukkan perubahan ukuran bulir spekel pada variasi konsentrasi. Berdasarkan grafik tersebut terlihat bahwa ukuran bulir spekel bergantung pada konsentrasi lapisan lilin lebah yang digunakan. Hal tersebut dapat dilihat melalui fungsi transfer yang diperoleh yaitu $\mathrm{y}=-0,0425 \mathrm{x}+7,4692$, dimana $\mathrm{x}$ merupakan besaran untuk konsentrasi emulsi lilin lebah dan y adalah besaran untuk ukuran bulir spekel. Fungsi tersebut menunjukkan bahwa setiap kenaikan konsentrasi $1 \%$ mengakibatkan perubahan nilai ukuran bulir spekel sebesar $0,0425 \mu \mathrm{m}$. Nilai 7,4692 merupakan nilai offset yang menyatakan bahwa ukuran bulir spekel buah tomat sebelum lapisi emulsi lilin lebah adalah sebesar 7,4692 $\mu \mathrm{m}$. Nilai koefisien kolerasi $\left(\mathrm{R}^{2}\right)$ 0,9362 mengindikasikan adanya korelasi yang kuat antara ukuran bulir dengan konsentrasi lapisan lilin lebah. Hal ini disebabkan karena semakin tinggi konsentrasi lapisan lilin lebah jumlah pori pada permukaan buah tomat akan berkurang, sehingga pola spekel yang terbentuk menjadi semakin rapat seperti yang terlihat pada Gambar 3. 


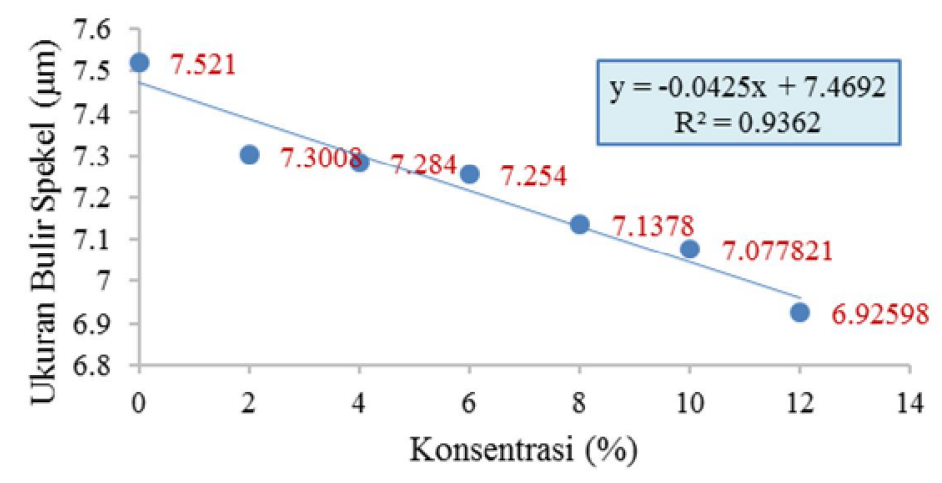

Gambar 5 Ukuran bulir spekel berdasarkan variasi konsentrasi pada buah tomat

\subsection{Korelasi Ukuran Bulir Spekel dengan Nilai Kontras}

Ukuran bulir spekel dan nilai kontras pada buah tomat yang dilapisi emulsi lilin lebah memiliki kecendrungan yang sama. Hal tersebut dapat dilihat pada Gambar 6 .

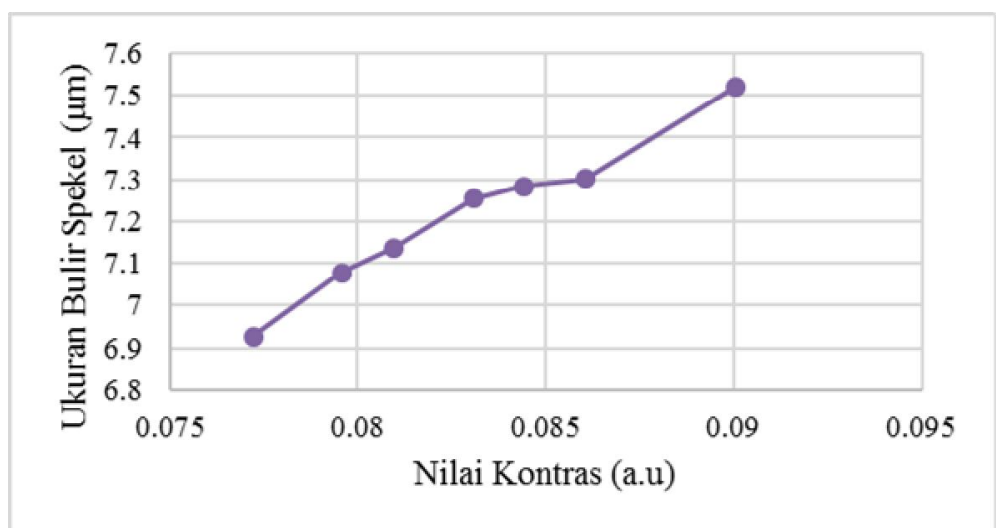

Gambar 6 Korelasi ukuran bulir spekel dengan nilai kontras

Gambar 6 menunjukkan korelasi ukuran bulir spekel dengan nilai kontras. Ukuran bulir spekel sebanding dengan nilai kontras, dimana setiap kenaikan nilai kontras maka ukuran bulir spekel juga akan naik. Bertambahnya konsentrasi lapisan lilin lebah membuat lapisan yang terbentuk semakin rapat, sehingga hamburan cahaya yang ditangkap semakin lemah. Hal ini membuat ukuran bulir dan kontras spekel menjadi semakin kecil.

\section{KESIMPULAN}

Lapisan lilin lebah pada buah tomat dapat dideteksi menggunakan sistem LSI dengan analisa perubahan nilai kontras dan ukuran bulir spekel, dimana nilai kontras sebanding dengan ukuran bulir spekel. Kenaikan konsentrasi membuat nilai kontras dan ukuran bulir semakin kecil.

\section{DAFTAR PUSTAKA}

Ansari, Z.M., and Nirala, A.K., 2012, Activity Assessment of Fruits Using the Methods of Inertia Moment and Absolute Value of the Diffrences, Journal of Advanced Laser and Optics Research, Vol. 1, hal 7-16.

Apsari, R., 2009, Sistem Fuzzy Berbasis Laser Speckel Imaging untuk Deteksi Mutilasi Enamel Gigi Akibat Paparan Laser ND: Y AG, Disertasi, PPs, Universitas Airlangga, Surabaya.

Boas, D. A., and Dunn, A. K., 2010, Laser Speckle Contrast Imaging in Biomedical Optics, Journal of Biomedical Optics, Vol. 15(1), 011109.

Chipouline, A., 2011, Spatial Noise and Speckel, abbe School of Photonics, Freidrich-Schiller Universitat. 
Goodman, J.W., 1975, Statistical Properties of Laser Speckle Patterns, Laser Speckle and Related Phenomena, J.C. Dainty, Ed., pp. 9-75, Springer-Verlag, Berlin.

Goodman, J.W., 1976, Some Fundamental Properties of Speckel Journal of Optical Society of America, Vol. 66, No. 11, 1145-1150.

Harmadi, 2011, Aplikasi Pola Spekel Akusto-Optik untuk Pendeteksian Vibrasi Akustik pada Dental Plaque Biofilm, Disertasi, PPs, Unversitas Airlangga, Surabaya.

Rabal, H.J., and Braga, R.A, 2009, Dynamic Laser Speckel and Application, Optical science and engineering: 139, Taylor \&Francis Group, LLC.

Roosmani, A.B., 1975, Percobaan Pendahuluan terhadap Buah-buahan dan Sayur-sayuran Indonesia, Buletin Penelitian Hortikultura LPH Pasar Minggu, 3(2):17-21, Jakarta.

Tamaki, Araie, Kawamoto, Eguchi, dan Fujji, 1994, Non-contact, Two Dimension Measurement of Retinal Microsirculation Using Laser Speckel Phenomenon, Invest. Opt. Mol. Vis. Sci., 35, 3825-34.

Winarno, F. G, dan Wirakartakusumah, M. A.., 1981, Fisiologi Lepas Panen, PT Sastra Hudaya, Jakarta.

Zdunek, A., Cybulska, J., 2011, Relation of Biospeckle Activity with Quality Attributes of Apples, Vol. 11, Sensors, hal 6317-6327.

Griot, M., 2005, Introduction to Laser Technology, http://www.mellesgriot.com, diakses Desember 2015.

Hartuti., 2006, Iptek Hortikultura, http://hortikultura.litbang.pertanian.go.id, diakses Maret 2016. 